\title{
REVIEW
}

\section{Physicians, subsequence and consequence}

\author{
W I McDonald
}

Based on the 2nd Meadows Memorial Lecture, given at the Royal College of Physicians, London, on the occasion of the meeting of the European Neuroophthalmological Society, in May 1997

The title of my lecture derives from a statement by the great lexicographer Dr Samuel Johnson in the course of a review of the Essay on Waters, by Dr Charles Lucas. ${ }^{1}$ Lucas extolled the healing powers of the waters at Bath (where he was physician) and elsewhere during an enforced hiatus in his political life in Dublin. Dr Johnson was evidently not persuaded: "It is incident to physicians, I am afraid, beyond all other men, to mistake subsequence for consequence."2

Like most Johnsonian aphorisms this one is at once arresting and amusing. One has an immediate sense that he is right - and as a physician, rightly, one is uncomfortable. But again typically, as one reflects on it, there are depths and complexities. Its force derives from the tension created between the perception that there is an important truth here, and the perception that it is not universal. In this lecture in which we celebrate the memory and contribution of a truly great physician, I want to explore some of these complexities, using Swithin Meadows as the exemplar - firstly, because he did not fall into the Johnsonian trap as Dr Lucas did; and secondly because these issues are deeply relevant to us and our patients today.

I first met Dr. Meadows in 1962 in Dunedin when he and Mr Douglas Northfield (the neurosurgeon) toured the main medical centres in New Zealand, and finally led a 2 day course on neurology in Auckland. His physical presence, his wisdom, his warmth and geniality, and his integrity made a profound impression, which was consolidated when, the following year, I came to Queen Square. To see him examine a patient conveyed a sense of a master craftsman at work. And to hear him lecture created a sense of inevitability of the soundness of his conclusions, based as they were on his perspicacious observation, deep knowledge, and long experience.

Nowhere was this better shown than in his lecture - which I first heard in Dunedin - on the neurology of visual failure. As Ralph Ross Russell, his successor at the Moorfields Eye Hospital, observed, to hear Meadows talk about the neurology of visual failure was like hearing a successful farmer talk about the rota- tion of crops. If you did it his way, all would be well. And it was. The love of the land implied in this comment was a reality. In retirement he and his wife Anne spent much time in a remote cottage in the West Country, accessible by a dirt track, and then only in fine weather.

His earlier career was marked by his outstanding ability, conspicuously shown when, against all expectations (including his own) he was appointed to a post as Medical Registrar at St Thomas's Hospital over the heads of that august institution's own graduates: a considerable feat in the early 1930s. He soon moved to Queen Square, where his mentors included many whose names are familiar in neuro-ophthalmology: Holmes, Adie, Collier, and Symonds. The residents at that time often discussed to whom they would go if they were neurologically ill themselves. The consensus was that they would get Symonds to take the history, Holmes to perform the physical examination, and Adie to interview the relatives because he was such a nice man.

Meadows was appointed Physician to the Westminster Hospital in 1938, and in 1939 to the Maida Vale Hospital. He moved to Queen Square in 1946 and was appointed to the Moorfields Eye Hospital in 1955. This latter post shaped his interests and determined the contribution for which he is best remembered. He would be gratified that this lecture which he endowed and is given biennially and related alternately to Moorfields and Queen Square, is being given this year in association with the European Neuro-ophthalmology Society's meeting. Though one of the outstanding general neurologists of his day, whose opinion was widely sought, his special affection was for the disorders of the visual system. He had, however, a personal aversion to the name "neuro-ophthalmology", observing that one might as well define a subject of "neuro-foot" to deal with the neurological disorders of that structure. But we must not take offence: his commitment to our subject - whatever we call it - was real.

Let us come back to Dr. Johnson's aphorism and consider it in a little more detail. First, subsequence. Though Johnson rightly - as I shall illustrate later - viewed as harmful the use to which doctors often put the principle when assessing treatment, it is nevertheless at the heart of the diagnostic and prognostic process. Let me illustrate with Meadows's own work. His first major paper was with Sir 
Charles Symonds, on tumours at the formen magnum. ${ }^{3}$ They clearly defined a pattern of symptomatic evolution and physical signs which would convince the physician that subsequently a tumour would be found at this site. It is interesting to note that in 1937, Symonds and Meadows clearly identified in one of their cases the down-beating nystagmus which later came to be recognised as characteristic of caudal medullary lesions:

"At rest there was a continuous vertical nystagmus which was evident also on lateral deviation of the eyes in either direction and on downward deviation, but absent on upward movement. This nystagmus had a range of about $1 \mathrm{~mm}$ and a frequency of about 2 per second. Associated with the vertical movement was a slight anticlockwise element."

At operation, $\mathrm{Mr}$ Julian Taylor found a vertebral artery aneurysm compressing the medulla and the upper spinal cord. From their analysis of the features of this and other cases they concluded that the nystagmus was associated with damage to the lower medulla.

Other papers showed that a particular pattern of history and signs would by the principle of subsequence be found to indicate the presence of an intracavernous aneurysm ${ }^{4}$; another pattern a pituitary adenoma ${ }^{5}$; and yet another an ischaemic lesion of the optic nerve in elderly people. ${ }^{6}$

\section{Acute optic neuritis in childhood}

One of Meadows' best known contributions was concerned with the optic nerve, in childhood. ${ }^{7}$ In 1969 the ophthalmological profession recognised his outstanding contribution to understanding, teaching, and practice in their field by inviting him to give the Doyne Lecture which is given annually in memory of Robert Doyne, the founder of the Oxford Ophthalmogical Congress. This lecture again illustrates the role of the principle of subsequence in making a diagnosis, and in assigning prognosis.

Meadows reviewed a personal series of 24 cases seen in the acute stage. He noted that the condition was usually bilateral, that the prognosis for vision was good, that sometimes there was more widespread acute involvement of the central nervous system than is usual in adult optic neuritis, and that subsequent development of multiple sclerosis was infrequent. These conclusions fitted broadly with an earlier series from New York $^{8}$ and were subsequently confirmed by further follow up of his cases together with those of Hierons and $\mathrm{Lyle}^{9}$ which we undertook in $1982,{ }^{10}$ and by a new series ${ }^{11}$ we reviewed with our Great Ormond Street colleagues in 1988. The low risk (10-15\%) of developing multiple sclerosis was not found by Haller and Patzold, ${ }^{12}$ perhaps because three quarters of their cases were unilateral whereas in the other studies mentioned the great majority were bilateral. Our figures for the risk of developing multiple sclerosis must be viewed with some caution, as the studies are retrospective and cases have been lost to follow up. They are, however, in accord with recent data from the Mayo Clinic, ${ }^{13}$ and it is I think, safe to conclude that the risk of multiple sclerosis for children with bilateral optic neuritis is clearly lower than after adult unilateral optic neuritis, as you will shortly see.

\section{Acute unilateral optic neuritis in adults}

This condition has been an abiding interest since I first joined the staff of the Moorfields Eye Hospital in 1969, and for two reasons. Firstly, the clinical problem is an important one, acute optic neuritis being one of the commonest causes of spontaneously reversible visual loss in early adult life. Secondly, with my physiological background I have a deep interest in mechanism and optic neuritis provides an ideal model in which to explore it, not only for itself, but for the light it sheds on multiple sclerosis, of which it is so often a part. I shall devote the remainder of this lecture to discussing some of the clinical issues surrounding optic neuritis, how the study of it illuminates the mechanism of relapse and remission in multiple sclerosis, and finally whether and how it should be treated.

Optic neuritis is a source of considerable alarm for the sufferer, who may wake in the morning, having gone to bed normal to find that she (for it is more often a woman than a man) is unable to see clearly. The vision usually deteriorates further over the next few days, often accompanied by discomfort which may have preceded it. By the time the physician first sees the patient, the anxious individual has a number of questions: What is the matter? Will I get better? Will the symptoms recur? Will I develop multiple sclerosis? Should I be treated?

Let us consider these questions in turn.

WHAT IS THE MATTER?

The diagnosis of optic neuritis is relatively easy and I need not rehearse it to this audience. It is, however, difficult for us as physicians - I use the term generically, as Johnson did, and so include ophthalmologists - to appreciate what the experience of the disease is like for the sufferer. A better understanding of it makes for a compassionate handling of the patient, a feature so noticeable in Swithin Meadows's relationship to his patients. This situation has changed as a result of the paintings and writings of Peter MacKarell, a lecturer in fine art at Goldsmiths College of the University of London. He had a series of episodes of optic neuritis and subsequently developed multiple sclerosis. I cannot do better than to read selections from his account, ${ }^{14}$ which should be consulted because it is accompanied by the revealing images, some of the originals of which are now at Guy's Hospital and others at Moorfields Eye Hospital.

"One evening my lad asked me to look up a word in the French dictionary and I found that I could not make out the print because at each point I attempted to focus, the individual letters were obscured by an infuriating and irritating bouncing grey dot.... The next day, upon waking I discovered that there was over the central zone of vision of 
my right eye, what seemed like a grey asbestos mat....In three days all response was lost."

After about two weeks, he began to improve. "I became aware that through the murk I could make out the fingers of my right hand as I waggled them in front of my right eye. The feeling was like peering through a thick screen of dirty net curtains or butter muslin... when the ophthalmoscope was shone into my right eye I was delighted to note that the bead of light appeared as a lovely cobalt blue. It seemed to shine like an astronomic phenomenon in interstellar space. (Later) I began to notice that my appreciation of space was wayward.... To my amazement I became aware that as I lay in bed that the metal curtain rail which surrounded the bed-space seemed to wobble in and out of the background of the opposite wall. There was an arch opposite and far from receding the way a "dark" or "void" normally does this shape too lurched and obtruded, seemingly advancing out of the background. There was a window in this arch and it seemed that the same mutinous quality made it refuse to 'sit' in space. Surfaces appeared liquid rather than solid...."

He made a virtually full recovery, but later had a second episode. He was at the Royal Ballet with his daughter for a performance of Cinderella. Through the newly affected eye the Ugly Sisters dressed for the ball

"...were quite transformed - to me they shimmered and glittered in an unreal spectacle that was, if anything, staggeringly beautiful... I began to really enjoy the iridescence for it was like having a neoimpressionist painting - a Seurat or Signac magically dancing about in the visual field of the affected eye."

But some of the impressions were disturbing. A painting of his daughter in a park

"...records a strange, disturbing, recurrent (and perhaps the most enduring) feature which I call the "incipient dissolve". It is as if the coherence and integration of vision including the admission of light was about to fragment and fade like a cinematic device."

The signs of optic neuritis are too well known to need description here, and I have reviewed them elsewhere (a coloured reproduction of one of MacKarrel's paintings is included). ${ }^{15}$ Taken together, the symptoms and signs usually permit a confident answer at the end of the first consultation to the patient's question: "What is the matter with me?" "Optic neuritis."

WILL I GET BETTER?

There have been many reports of the prognosis for vision in optic neuritis. ${ }^{16-22} 23$ There is general agreement that about $90 \%$ of patients make a good recovery, with Snellen acuities of $6 / 9$ or better. No factors have been consistently shown to be predictive of a poor outcome. Miller et al found that long lesions ( $\geqslant 5 \mathrm{~cm}$ ) as determined by MRI which included involve- ment of the intracanicular portion of the optic nerve were associated with a significantly slower or poorer outcome. In a subsequent study $^{21}$ in which MRI was performed both at presentation and later, these correlations were found to apply to the characteristics of the late lesion, but not to those at presentation

WILL IT RECUR?

There is a wide range in the reported frequency $(14 \%$ to $32 \%)$ with which optic neuritis recurs. ${ }^{182-25}$ A reasonable answer in the clinic to the question "Will it recur? " is that there is roughly a one in four chance that it will, though one can add the reassurance that it is to be expected that recovery will again be good.

WILL I DEVELOP MULTIPLE SCLEROSIS?

This question is being asked with increasing frequency as patients become more knowledgeable. That multiple sclerosis may subsequently develop after optic neuritis is a fact recorded in history long before the disease itself was described. Augustus D'Este, one of King George III's illegitimate grandchildren, developed a relapsing and remitting neurological illness in 1822, and kept a detailed diary of his symptoms and the treatments which he received. ${ }^{26}$ This is how he described the early days of his illness.

"In the month of December 1822 I travelled from Ramsgate to the Highlands of Scotland for the purpose of passing some days with a Relation for whom I had the affection of a Son. On my arrival I found him dead.... Shortly after the funeral I was obliged to have my letters read to me, and their answers written for me, as my eyes were so attacked that when fixed upon minute objects indistinctness of vision was the consequence:- Until I attempted to read, or to cut my pen, I was not aware of my Eyes being in the least attacked. Soon after, I went to Ireland, and without anything having been done to my Eyes, they completely recovered their strength and distinctness of vision....

October 17, 1827 To my surprise (in Venice) I one day found a torpor or indistinctness of feeling about the Temple of my left Eye. At Florence I began to suffer from a confusion of sight:- about the 6 th of November the malady increased to the extent of my seeing all objects double. Each eye had its separate visions. - Dr. Kissock supposed bile to be the cause: I was twice blooded from the temple by leeches; purges were administered; One Vomit, and twice I lost blood from the arm: one of the times it was with difficulty that the blood was obtained. - The Malady in my Eyes abated, I again saw all objects naturally in their single state. I was able to go out and walk. Now a new disease began to show itself: every day I found gradually (by slow degrees) my strength leaving me. - A torpor or numbness and want of sensation became apparent about the end of the Back-bone and the Perinaeum. At length about the 4 th of December my strength of legs had quite 
Multiple sclerosis after optic neuritis

\begin{tabular}{|c|c|c|}
\hline & Observed \% & Predicted $\%$ \\
\hline \multicolumn{3}{|l|}{ United States } \\
\hline Kurland et al $1966^{34}$ & 13 & \\
\hline Taub and Rucher $1954^{35}$ & 32 & \\
\hline Collis $1965^{36}$ & 36 & \\
\hline$\left\{\right.$ Cohen and Lessell 1979 (mean follow up 7 y) ${ }^{37}$ & 35 & \\
\hline$\star\{\text { Rizzo and Lessell } 1988 \text { (mean follow up } 14.9 \mathrm{y})^{24}$ & 58 & \\
\hline Males & & 34 \\
\hline Females & & 74 \\
\hline Rodriguez et al $1995^{19}$ & & 60 (at $40 \mathrm{y}$ ) \\
\hline \multicolumn{3}{|l|}{ United Kingdom } \\
\hline Hutchinson $1976^{38}$ & 51 & 78 (at $15 \mathrm{y})$ \\
\hline$\{$ Compston et al 1978 (mean follow up 4 y) & 40 & 60 (at 8 y) \\
\hline$\star\{\text { Francis et al } 1987 \text { (mean follow up } 11.6 \mathrm{y})^{23}$ & 57 & 75 (at $15 \mathrm{y}$ ) \\
\hline \multicolumn{3}{|l|}{ Scandinavia } \\
\hline Kinnunen $1983^{40}$ & 19 & \\
\hline Usimaa & & 38 (at $9 \mathrm{y}$ ) \\
\hline Vassa & & 24 (at 9 y) \\
\hline Sandberg-Wollheim $1990^{25}$ & 38 & 45 (at $15 y$ ) \\
\hline \multicolumn{3}{|l|}{ Australia } \\
\hline Rischbeith $1968^{41}$ & 73 & \\
\hline Landy $1999^{43}$ & & \\
\hline Hely et al $1986^{44}$ & 32 & 42 (at $7 \mathrm{y}$ ) \\
\hline \multicolumn{3}{|l|}{ Japan } \\
\hline Isayama et al $1982^{45}$ & 8.3 & \\
\hline
\end{tabular}

$\star\{=$ same cohort. optic nerves; and in Ulrich and GroebkeLorenz's series of 36 cases only one did not show demyelination in the optic nerves. ${ }^{33}$

But patients want to know what the risk is for them. This is more difficult to determine than it might seem, as the figures in the table show. Several factors are likely to contribute. Firstly, there is the selection of patients: the survey of Kurland et $a l,^{34}$ for example, was based on the follow up of male war veterans in the United States. Many studies are not truly prospective, and in sequential follow up, cases have been lost, thus potentially introducing bias; the Sandberg-Wollheim ${ }^{25}$ study in Scandinavia and Landy's Australian studies ${ }^{42}{ }^{43}$ were, however, prospective and yielded figures of about $50 \%$. The duration of follow up, diagnostic criteria, geographical location and race also vary, and may influence the results. The very low risk in $\operatorname{Japan}^{45}(8 \%)$ probably reflects the low prevalence of multiple sclerosis among orientals, probably on a genetic basis.

It is safe to conclude that the risk for orien-

left me... I remained in this extreme state of weakness for about 21 days...."

All this occurred a decade before Carswell ${ }^{27}$ first drew then published the first depiction of the lesions of multiple sclerosis. ${ }^{28}$

The first medical description I have found of what may be multiple sclerosis subsequent to optic neuritis, also precedes Carswell's description. It dates from 1840 and is to be found in the third edition of William McKenzie's A practical treatise on diseases of the eye. ${ }^{29}$ Here he describes several cases of remitting visual loss in young people, compatible with optic neuritis, and one patient with additional neurological features. He was a 23 year old man who

“...was admitted into St. Bartholomew's Hospital, on account of a palsy of his limbs",

which had evolved progressively over the preceding six months. He had, at the commencement of his illness,

"...a(progressive) confusion of vision (so that) he could discern no object distinctly."

McKenzie describes how he was incontinent and was developing an asymmetric weakness of the arms and dysarthria. After 3 weeks in hospital and frequent purges he began to improve. After 2 months

"...he could move his hands and arms nearly as well as ever; and his eyesight was so much improved that he could read a newspaper...the functions of the bladder were completely restored; (and) his speech became articulate."

The late 19 th century neurologists knew well that visual loss was an important manifestation of multiple sclerosis. A Mayo Clinic survey ${ }^{30}$ in the middle of this century and a personal survey of cases at the Maida Vale Hospital in $1980^{31}$ indicated that acute optic neuritis occurred in the course of multiple sclerosis in about $75 \%$ of cases. As to pathology, Lumsden ${ }^{32}$ reported that all of 35 postmortems showed optic nerve involvement. JG Greenfield once told William Blackwood (who told me) that he had once (but only once) seen a postmortem case without involvement of the tals is low and that the risk for occidentals is variable, but for people of northern European origin is probably not less than $50 \%$ after prolonged follow up, and may in some places be higher.

\section{RISK FACTORS}

Can one predict the likelihood that a patient will develop multiple sclerosis? Several risk factors have been studied, but only three have been consistently shown to be of value: the finding of oligoclonal bands in the CSF, ${ }^{25} 4647$ retinal perivenous sheathing, and cerebral MRI. The last two deserve further comment.

Retinal perivenous sheathing as a risk factor was first reported by Lightman et $a l^{48}$ in a prospective study. They found a 14 -fold increase in risk after a mean of 3.5 years. Recently, Rodriguez et $a l^{19}$ confirmed this observation, albeit at a rather lower level of significance, perhaps because of the retrospective nature of the study. The most studied prognostic factor is the presence of "silent" cerebral lesions at MRI in patients presenting with clinically isolated optic neuritis. The results of numerous investigations are highly consistent. ${ }^{49}$ At the Institute of Neurology, David Miller and his colleagues have been following up a cohort of patients now for 10 years. They have found that the presence of such "silent" cerebral lesions is of predictive value even after 1 year, ${ }^{50}$ and after 10 years, $89 \%$ of those with such lesions at presentation have developed multiple sclerosis, whereas only $7 \%$ of those without such lesions have done so. ${ }^{51}$

\section{Bilateral optic neuritis in adults}

This is much less common than acute unilateral optic neuritis. The long term follow up of the cases of Heirons and Lyle ${ }^{9}$ already referred to $^{10}$ raised the possibility that multiple sclerosis might be less frequent than after unilateral optic neuritis. This survey was conducted before genetic testing for Leber's optic atrophy was available, and we therefore undertook a review of a personal series of 23 cases seen over the past 20 years or so. ${ }^{52}$ The mean duration of 
follow up was 6 years. Mitochondrial DNA analysis disclosed that four of these cases had a pathogenic Leber's mutation without a family history of clinical expression. Five had developed multiple sclerosis and the remaining 14 still had isolated optic neuropathy. The numbers are small, but the results lend some support to the suggestion that multiple sclerosis may be less frequent after bilateral than unilateral optic neuritis. However, it occurs sufficiently often for prudence to dictate a cautious prognosis.

\section{OPTIC NEURITIS AS A MODEL OF MULTIPLE}

SCLEROSIS

I turn now to my other interest in optic neuritis: its role as a model for studying mechanism in demyelinating disease generally, and in multiple sclerosis in particular. As we have seen, recovery after optic neuritis is usual, as after acute relapses of multiple sclerosis. Optic neuritis thus provides an excellent opportunity to investigate the mechanisms of relapse and remission.

It is in the nature of clinical research that one is dependent on the chance occurrence of disease and of the patient presenting with it. Thus, one is often dependent on data from different sources to make a coherent story. It is important therefore to summarise the reasons why I think it is legitimate to use observations on optic neuritis to illuminate multiple sclerosis. Firstly, there is the frequency with which optic neuritis is indeed a part of multiple sclerosis. Secondly, there is the evidence that the characteristic pathology in both is demyelination. This can be seen directly at postmortem in the case of optic neuritis in the course of multiple sclerosis, and can be inferred from the observation of delayed visual evoked potentials in isolated optic neuritis. Thirdly, there are close similarities in the pathology in the brain and optic nerve in multiple sclerosis. Finally, there is evidence that the inflammation is immunologically mediated at both sites.

It is now appropriate to consider what we have learnt from the study of optic neuritis and multiple sclerosis about the development of symptoms and recovery in both. It has been possible to shed light on these problems by combining clinical, electrophysiological, magnetic resonance, and pathological studies. We have been in a privileged position at Queen Square having an NMR Research Unit set up by the Multiple Sclerosis Society of the UK and Northern Ireland with additional support from the Medical Research Council. Here there is a wide range of expertise in neurology, radiology, and physics; important collaborations have been developed with neuropathology, clinical neurophysiology, neuropsychology, and neuropsychiatry.

It is well established that the areas of high signal on proton density and T2 weighted MR imaging of the brain correspond with plaques. ${ }^{53}$ Injection of the contrast agent gadolinium-DTPA often (especially at times of clinical relapse) shows that some lesions enhance at a time when others do not. Enhancement represents a focal breakdown of the blood-brain barrier and pathological studies of postmortem and biopsy material indicate that this breakdown is seen in association with focal inflammation. ${ }^{556}$ Frequent serial scanning (often at weekly, fortnightly, or monthly intervals) has allowed us to identify the sequence of events in the evolution of the new lesion in multiple sclerosis. The earliest detectable event in most lesions is a focal breakdown of the blood-brain barrier which may occur in otherwise MRI-normal white matter. ${ }^{57}$ The lesion increases in size to reach a maximum at 4-6 weeks. ${ }^{58}$ Most lesions cease enhancing at this stage and then decrease in size to leave a smaller residual abnormality after 2 to 3 months. ${ }^{58}$ Quantitative studies have shown that, as expected, the waxing and waning element of the lesion is due to oedema. ${ }^{60}$ Experimental and human studies indicate that the abnormal signal of the residual lesion arises from changes in the amounts of intracellular and extracellular water as a consequence of gliosis and a variable amount of tissue loss. ${ }^{6162}$

The application of short-echo time spectroscopy to new lesions indicates that demyelination begins during the active inflammatory phase, as judged by gadolinium-DTPA enhancement. ${ }^{63}$ The myelin breakdown products are removed over the subsequent 6-8 months. Evoked potential studies within 24 hours of the onset of symptoms in optic neuritis provide evidence that demyelination is already present at this time. The serial study of such patients allows one to relate the changes in function to the changes in pathology as shown by NMR methods. ${ }^{64}$ In a series of 10 patients with acute optic neuritis (one bilateral) studied within 2 weeks of the onset of symptoms and before the onset of recovery, all 11 optic nerves were found to enhance. A month later, enhancement had ceased in all but two of the nerves, indicating that the natural history of enhancement in acute isolated optic neuritis is similar to that of the lesions in the brain in multiple sclerosis. The clinical features of optic neuritis (pain, reduced acuity, impaired colour vision, afferent pupillary defect) occurred during the enhancing - that is, the inflammatory phase.

Of particular interest were the electrophysiological findings. At presentation, there was a marked reduction in the amplitude (signifying conduction block in most fibres) from the affected nerve. What remained of the evoked potential was, however, delayed indicating that demyelination was already established. A month later the amplitude of the evoked potential had increased indicating that conduction had been restored in many fibres. It is well established experimentally that acute demyelination produces conduction block. ${ }^{65}{ }^{66}$ The present observations make it clear that conduction can be restored while demyelination is still present. The difference in the state of the nerve at the two recording times is that there was inflammation (as judged by gadolinium enhancement) at the early stage (when conduction block was severe), but not at the later stage. Because demyelination was present at both times, these observations suggest that the 
inflammatory process itself contributes to conduction block. Two questions now arise:

(1) What elements of the inflammatory process produced conduction block? Recent experiments on the rat spinal cord have provided evidence that nitric oxide (which is produced in abundance by macrophages, which are a prominent part of the acute lesions in multiple sclerosis) has a concentration related blocking effect on demyelinated and normal fibres. ${ }^{67}$

(2) What is the mechanism of conduction in persistently demyelinated fibres? New sodium channels can be inserted into the axonal membrane in demyelinated internodal segments of central and peripheral nerve fibres. ${ }^{68}{ }^{69}$ It seems likely that these channels mediate the restoration of (slowed) conduction which has been demonstrated experimentally. ${ }^{70}$ In multiple sclerosis, lesions in which demyelinated axons survive show a marked increase in saxitoxin binding, indicating a marked increase in the density of sodium channels. ${ }^{72}$ Lesions in which most axons have degenerated do not show such an increase in binding. It therefore seems likely that in multiple sclerosis, as in experimental lesions, the restoration of conduction which underlies the restoration of function depends to an important extent on the development of new sodium channels in the demyelinated axons.

There is evidence that remyelination occurs in the CNS and that in some lesions it may be extensive. ${ }^{7374}$ The persistence of marked delays in evoked potentials in patients with optic neuritis or multiple sclerosis indicate that remyelination is not essential for recovery. Subsequent shortening of the latency, ${ }^{75}$ particularly in children, ${ }^{11}$ suggests that remyelination may play some part in maintaining function later.

To sum up, inflammation and demyelination occur early in the development of the new lesion. Both these processes contribute to the development of conduction block and therefore of symptoms. This is the mechanism of relapse. In the succeeding weeks new sodium channels are formed in the demyelinated axons. When the inflammation subsides, conduction is restored and the symptoms resolve. This is the mechanism of remission.

We turn now to our patient's last question.

SHOULD I BE TREATED, AND, IF SO, HOW?

This brings up in stark form the other aspect of Dr Johnson's aphorism - the one he intended us to see when he was reviewing Dr Lucas's claims for the therapeutic benefits of the waters: the danger of mistaking subsequence for consequence.

We have seen that about $90 \%$ of patients with acute optic neuritis recover well without treatment. The question is whether one can improve on that? A variety of forms of steroid treatment have been studied. They have consistently shown that the duration of visual impairment is shortened but that visual outcome is unchanged. An apparent exception to the latter was the United States Optic Neuritis Study Group's 6 month report, ${ }^{18}$ but after
12 months of follow up there was no difference between the actively treated and the placebo treated groups. $^{76}$

A surprising finding in the first report $\mathrm{t}^{18}$ was a decreased risk of recurrence of optic neuritis in patients treated with intravenous steroids as compared with those treated with oral steroids or placebo. An even more surprising later finding was that after 2 years the risk of progression from optic neuritis to clinically definite multiple sclerosis was higher in patients treated with oral steroids than in those treated with intravenous steroids. ${ }^{77}$ As an editorial in the New England fournal of Medicine at the time pointed out, this finding does not have an obvious biological explanation. ${ }^{78}$ It is to be noted that the conclusion was reached on the basis of a secondary analysis of a trial designed for another purpose, and that secondary analyses are notoriously vulnerable. Inspection of the Kaplan-Meier survival curves shows that the absolute numbers of patients in the different groups at the later periods of follow up was small. It was not therefore surprising that after a further 2 years of follow up the apparent difference between the frequency of development of multiple sclerosis in the treated groups had disappeared. ${ }^{79}$ Whether this apparent delay in the development of the clinically disseminated disease is significant awaits confirmation.

In the meantime, what should be one's approach to treatment? My policy is to treat optic neuritis with steroids when there is severe visual loss, either in bilateral optic neuritis or in unilateral optical neuritis when there is poor vision in the other eye from whatever cause. In this way the duration of functional impairment may be shortened. I generally use intravenous steroids, because the course is quickly completed. However, as the evidence that oral steroids increase the risk of developing of multiple sclerosis is equivocal, I think that it is reasonable to use oral steroids if that is more convenient for the patient.

\section{Conclusion}

In this saga, I suggest that we have fallen into the Johnsonian trap just as surely as Dr Lucas did. It is true that subsequent to treatment with one form of steroids more patients after 2 years did develop multiple sclerosis. But after 2 years in natural history studies, barely half of those who will develop multiple sclerosis have done so and the interval may be as long as 36 years, as in one of Landy's cases. ${ }^{43}$ I suggest that the small numbers simply did not allow us to conclude safely that the consequence of using intravenous steroids was to delay significantly the onset of the disseminated disease.

Dr Lucas knew no better, though Dr Johnson, more than 2 centuries ago could see where he went wrong. We should know better, thanks to the advances in measurement and medicine which derived from the great 19th century debates, ${ }^{80}$ Fisher's The Design of Experiments, ${ }^{81}$ and the power of the randomised trial so triumphantly demonstrated by Bradford Hill and his colleagues ${ }^{82}$ in 1948, at the time when Swithin Meadows was establishing himself at Queen Square. Now we have 
population based prevalence studies of multiple sclerosis from which we can derive the sample size and the time over which patients must be studied if we are reasonably to conclude that the good result of our treatment is a necessary consequence of what we have done..$^{83} 84$

Swithin Meadows would have endorsed this position. He was ever sceptical, but warmly welcomed new certainties. Those of us who were taught by him acquired respect for careful observation and cautious inference. $\mathrm{He}$ enriched our subject and we are all in his debt for his example and his legacy.

1 Lucas C. An essay on waters. 3 Vols. London: A Millar, 1756.

2 Johnson S. Review of Dr Lucas's essay on waters. Literary Magazine 1756;ii:39.

3 Symonds CP, Meadows SP. Compression of the spinal cord in the neighbourhood of the foremen magnum. Brain 1937;60:52-84.

4 Meadows SP. Intracavernous aneurysms of the internal carotid artery: their clinical features and natural history. Arch Ophthalmol 1959;62:566-74.

5 Meadows SP. Unusual clinical features and modes of presentation in pituitary adenoma, including pituitary apoplexy. Neuroophthalmology 1968;4:178-89.

6 Meadows SP. Blindness due to occlusive arterial disease. Trans Ophthalmol Soc UK 1965;85:251-8.

7 Meadows SP. Doyne Memorial Lecture (1969): Retrobulbar and optic neuritis in childhood and adolescence. Transactions of the Ophthalmological Society of the UK 1969;89: 603-38.

8 Kennedy C, Carter S. Relation of optic neuritis to multiple sclerosis in children. Pediatrics 1961;28:377-87.

9 Hierons R, Lyle TK. Bilateral retrobulbar optic neuritis. Brain 1959;82:56-67.

10 Parkin PJ, Hierons R, McDonald WI. Bilateral optic neuritis: a long-term follow-up. Brain 1984;107:951-64.

11 Kriss A, Francis DA, Cuendet F, et al. Recovery after optic neuritis in childhood. $\mathcal{F}$ Neurol Neurosurg Psychiatry 1988;51:1253-8.

12 Haller P, Patzold U. Die Optikusneuritis im Kiudersalter. Forschritte der Neurologle und Psychiatrie 1979;47:209-16.

13 Luccinetti CF, Kiers L, O'Duffy A, et al. Risk factors for developing multiple sclerosis after childhood optic neuritis. Neurology 1997;49:1413-18.

14 MacKarell P. Interior journey and beyond: an artist's view of optic neuritis. In: RF Hess, Plant GT, eds. Optic neuritis. Cambridge: Cambridge University Press, 1986 283-93.

15 McDonald WI, Barnes D. The ocular manifestations of multiple sclerosis. I. Abnormalities of the afferent visual system. F Neurol Neurosurg Psychiatry 1992;55:747-52.

16 Earl CJ, Martin B. Prognosis in optic neuritis related to age. Lancet 1967;i:74-6.

17 Gould ES, Bird AC, Leaver, PK, et al. Treatment of optic neuritis by retrobulbar injection of triamcinolone. $B M Y$ 1977;i:1495-7.

18 Beck W, Cleary DA, Anderson MM, et al. A randomized, controlled trial of corticosteroids in the treatment of acute optic neuritis. N Engl F Med 1992;326:581-8.

19 Rodriguez M, Siva A, Cross SA, et al. Optic neuritis: a population based study in Olmsted County, Minnesota. Neurology 1995;45:244-50.

20 Miller DH, Newton MR, van der Poel JC, et al. Magnetic resonance imaging of the optic nerve in optic neuritis. Neurology 1988;38:175-9.

21 Kapoor R, Miller DH, Jones SJ, et al. Effects of intravenous methylprednisolone on outcome in MRI-based prognostic subgroups in acute optic neuritis. Neurology 1998;50: 230-7.

22 Bradley WG, Whitty CWM. Acute optic neuritis: prognosis for development of multiple sclerosis. $\mathcal{F}$ Neurol Neurosurg Psychiatry 1968;31:10-18.

23 Francis DA, Compston DAS, Batchelor JR, et al. A reassessment of the risk of multiple sclerosis developing in patients with optic neuntis after extended follow up. $\mathcal{F}$ Neurol Neurowith optic neuntis after extended
surg Psychiatry 1987;50:758-65.

24 Rizzo JF, Lessell S. Risk of developing multiple sclerosis after uncomplicated optic neuritis: a long term prospective study. Neurology 1988;38:185-90.

25 Sandberg-Wollheim M, Bynke H, Cronqvist S, et al. A longterm prospective study of optic neuritis: evaluation of risk factors. Ann Neurol 1990;27:386-93.

26 Firth D. The case of Augustus D'Este. Cambridge: Cambridge University Press, 1948.

27 Carswell R. Pathological anatomy: illustrations of the elementary forms of the disease. London: Longmans, 1838

28 Compston DAS. The dissemination of multiple sclerosis. $\mathcal{F}$ $R$ Coll Physicians Lond 1990;24:207-18.

29 McKenzie W. A practical treatise on diseases of the eye. $3 \mathrm{rd} \mathrm{ed}$ London: Longman, 1840.

30 Ivers RR, Goldstein NP. Multiple sclerosis: a current appraisal of symptoms and signs. Proc Mayo Clin 1963;38
457-66.
31 Shibasaki H, McDonald WI, Kuroiwa Y. Racial modification of clinical picture of multiple sclerosis: comparison between British and Japanese patients. $\mathcal{F}$ Neurol Sci 1981;49:253-71.

32 Lumsden CE. The pathology of multiple sclerosis. In: Vinken PJ, Bruyn GW, eds. Handbook of clinical neurology: multiple sclerosis and other demyelinating diseases. Amsterdam: North-Holland, 1970;9:217-309.

33 Ulrich J, Groebke-Lorenz W. The optic nerve in multiple clerosis: a morphological study with retrospective clinicopathological correlations. Neuroophthalmology 1983;3: $149-59$

34 Kurland LT, Beebe GW, Kurtzke JF, et al. Studies on the natural history of multiple sclerosis. 2 . The progression of optic neuritis to multiple sclerosis. Acta Neurol Scand 1966; 42(suppl 19):157-76.

35 Taub RG, Rucker CW. The relationship of retrobulbar neuritis to multiple sclerosis. Am $\mathcal{F}$ Ophthalmol 1954;37:494-7.

36 Collis WJ. Acute unilateral retrobulbar neuritis. Arch Neurol 1965;13:409-12.

37 Cohen MM, Lessell S, Wolf PA. A prospective study of the risk of developing multiple sclerosis in uncomplicated optic neuritis. Neurology (Minneapolis) 1979;29:208-13.

38 Hutchinson WM. Acute optic neuritis and the prognosis for multiple sclerosis. F Neurol Neurosurg Psychiatry 1976;39: 283-9.

39 Compston DAS, Batchelor JR, Earl CJ, et al. Factors influencing the risk of multiple sclerosis developing in patients with optic neuritis. Brain 1978;101:495-511.

40 Kinnunen $\mathrm{E}$. The incidence of optic neuritis and its prognosis for multiple sclerosis. Acta Neurol Scand 1983;68:371-7.

41 Rischbeith RHC. Retrobulbar neuritis in the state of South Australia. Proc Aust Assoc Neurol 1968;5:573-5.

42 Landy PJ. A prospective study of the risk of developing multiple sclerosis in optic neuritis in a tropical and sub-tropical tiple sclerosis in optic neuritis in a tropical and su.
area. F Neurol Neurosurg Psychiatry 1983;46:659.

43 Landy PJ. The probability of developing multiple sclerosis following an episode of optic neuritis: a prospective study. $\mathcal{F}$ Clin Neurosci 1999 (in press).

44 Hely MA, McManis PG, Dorain TJ, et al. Acute optic neuritis: a prospective study of risk factors for multiple sclerosis. I Neurol Neurosurg Psychiatry 1986;49:1125-30.

45 Isayama Y, Takahashi T, Shimoyoma T, et al. Acute optic neuritis and multiple sclerosis. Neurology 1982;32:73-6.

46 Moulin D, Paty DW, Ebers GC. The predictive value of cerebrospinal fluid electrophoresis in possible multiple sclerosis. Brain 1983;106:809-16.

47 Söderström M, Ya-ping J, Hillert J, et al. Optic neuritis. Prognosis for multiple sclerosis from MRI, CSF and HLA findings. Neurology 1998;50:708-14.

48 Lightman S, McDonald WI, Bird AC, et al. Retinal venous sheathing in optic neuritis: its significance for the pathogenesis of multiple sclerosis. Brain 1987;110:405-14.

49 Miller DH, Albert PS, Barkhof F, et al. Guidelines for the use of magnetic resonance techniques in monitoring the treatment of multiple sclerosis. Ann Neurol 1996;39:6-16.

50 Miller DH, Ormerod IEC, McDonald WI, et al. The early risk of multiple sclerosis after optic neuritis. F Neurol Neurosurg Psychiatry 1988;51:1569-71.

51 O'Riordon JI, Thompson AJ, Kingsley DPE, et al. The prognostic value of brain MRI in clinically isolated syndromes of the CNS. A 10 year follow up. Brain 1998;121:495-503.

52 Morrissey SP, Borruat FX, Miller DH, et al. Bilateral simultaneous optic neuropathy in adults: clinical, imaging, serological, and genetic studies. F Neurol Neurosurg Psychiatry 1995;58:70-4.

53 Stewart WA, Hall LD, Berry K, et al. Correlation between NMR scan and brain slice data in multiple sclerosis. Lancet 1984;ii:412.

54 Ormerod IEC, Miller DH, McDonald WI. The role of NMR imaging in the assessment of multiple sclerosis and isolated neurological lesions: a quantitative study. Brain 987;110:1579-616.

55 Katz D, Taubenberger JK, Cannella B, et al. Correlation between MRI findings and lesion development in chronic active multiple sclerosis. Ann Neurol 1993;34:661-9.

56 Nesbit GM, Forbes GS, Scheithauer BW, et al. Multiple sclerosis: histopathologic and MR and/or CT correlation in 37 cases at biopsy and three cases at autopsy. Radiology 1991;180:467-74.

57 Kermode AG, Thomson AJ, Tofts P, et al. Breakdown of the blood-brain barrier precedes symptoms and other MRI signs of new lesions in multiple sclerosis: pathogenetic and clinical implications. Brain 1990;113:1477-89.

58 Willoughby EW, Grochawski E, Li DKB, et al. Serial magnetic resonance scanning in multiple sclerosis: a second prospective study in relapsing patients. Ann Neurol 1989;25:43-9.

59 Miller DH, Rudge P, Johnson G, et al. Serial gadolinium enhanced magnetic resonance imaging in multiple sclerosis. Brain 1988;111:927-39.

60 Larson HBW, Frederiksen J, Kjaer L, et al. In vivo determination of $T_{1}$ and $T_{2}$ in the brain of patients with severe but stable multiple sclerosis. Magn Reson Med 1988;7:43-55.

61 Barnes D, McDonald WI, Landon DN, et al. The characterization of experimental gliosis by quantitative
nuclear magnetic resonance imaging. Brain 1988;111:83-94.

62 Barnes D, Munro PMG, Youl BD, et al. The longstanding MS lesion. A quantitative MRI and electron microscopic study. Brain 1991;114:1271-80.

63 Davie CA, Hawkins CP, Barker GJ, et al. Serial proton magnetic resonance spectroscopy in acute multiple sclerosis
lesions. Brain 1994;117:49-8. 
64 Youl BD, Turano G, Miller DH, et al. The pathophysiology of acute optic neuritis: an association of gadolinium leakage with clinical and electrophysiological deficits. Brain 1991 114: $2437-50$

65 McDonald WI. The effects of experimental demyelination on conduction in peripheral nerve: a histological and electrophysiological study. II electrophysiological observations. Brain 1963;86:501-24.

66 McDonald WI, Sears TA. The effects of experimental demyelination on conduction in the central nervous system. Brain 1970;93:583-98.

67 Redford DJ, Kapoor R, Smith KJ. Nitric oxide donors reversibly block axonal conduction; demyelinated axons are especially susceptible. Brain 1997;120:2149-57.

68 England JD, Gamboni F, Levinson SR, et al. Changed distribution of sodium channels along demyelinated axons. Proc Natl Acad Sci USA 1990;87:6777-801.

69 Black JA, Felts P, Smith KJ, et al. Distribution of sodium channels in chronically demyelinated spinal cord axons: immuno-ultrastructural localisation and electrophysiological observations. Brain Res 1991;544:59-70.

70 Bostock H, Sears TA. The internodal axon membrane: electrical excitability and continuous conduction in segmental demyelination. F Physiol 1978;280:273-301.

71 Smith KJ, Felts PA, Baker TA. Conduction properties of glial-ensheathed and sparsely ensheathed central demyelinated axons. Ann Neurol 1994;36:287. [abstract]

72 Moll C, Mourre C, Lazdunski M, et al. Increase of sodium channels in demyelinated lesions of multiple sclerosis. Brain Res 1991;556:311-16.

73 Prineas J, Connell F. Remyelination in multiple sclerosis. Ann Neurol 1979;5:22-31.
74 Ozawa K, Suchanek G, Breitschopf H, et al. Patterns of oligodendroglial pathology in multiple sclerosis. Brain 1994; 117:1311-22

75 Jones SJ. Visual evoked potentials after optic neuritis. Effect of time interval, age and disease dissemination. F Neurol 1993;240:489-94.

76 Beck RW, Cleary PA. The Optic Neuritis Study Group. Optic neuritis treatment trial. Arch Ophthalmol 1993;111: Optic neu.

77 Beck RW, Cleary PA, Traub JD, et al. The effect of corticosteroids for acute optic neuritis on the subsequent development of multiple sclerosis. N Engl f Med 1993;329:1764-9.

78 Silberberg DH. Corticosteroids and optic neuritis. $N$ Engl f Med 1993;329:1808-10.

79 Beck RW, The optic neuritis treatment trial: three year follow up results. Arch Ophthalmol 1995;113:136.

80 Matthews JR. Quantification and the quest for medical certainty. Princeton: Princeton University Press, 1995.

81 Fisher RA. The design of experiments. Edinburgh: Oliver and Boyd, 1935

82 Streptomycin treatment of pulmonary tuberculosis. A Medical Research Council investigation. BMf 1948;ii: 769-82.

83 Weinshenker BG, Carriere W, Baskerville J, et al. The natural history of multiple sclerosis: a geographically based study. IV. Applications to planning and interpretation of clinical therapeutic trials. Brain 1991;114:1057-67.

84 Runmarker B, Andersen O. Prognostic factors in a multiple sclerosis incident cohort with 25 years of follow up. Brain 1993;116:117-34 